\title{
The role of mast cell tryptases in cardiac myxoma: Histogenesis and development of a challenging tumor
}

\author{
GIUSEPPE DONATO ${ }^{1}$, FRANCESCO CONFORTI ${ }^{1}$, CATERINA CAMASTRA $^{1}$, \\ MICHELE AMMENDOLA ${ }^{2}$, ANNALIDIA DONATO ${ }^{1}$ and ATTILIO RENZULLI ${ }^{3}$ \\ Departments of ${ }^{1}$ Pathology, ${ }^{2}$ Pharmacology and ${ }^{3}$ Cardiac Surgery, School of Medicine, \\ University Magna Graecia, Catanzaro I-88100, Italy
}

Received August 21, 2013; Accepted February 26, 2014

DOI: $10.3892 / 01.2014 .2104$

\begin{abstract}
A number of available studies have focused on the role of mastocytes and their angiogenic factors, such as tryptase expression, in cancer growth as a major research objective. Cardiac myxoma is a rare neoplasia and is the most common primary tumor of the heart. The cellular elements of cardiac myxoma have an endothelial phenotype; however, its histogenesis remains unclear. Currently, no available studies have correlated the pathological characteristics of cardiac myxomas, such as cell differentiation and vascularization, with the angiogenic factors of mast cells. The aim of the present study was to investigate the role of mast cell tryptases on the development of cardiac myxomas and examine the histogenesis of tumoral cells. A series of 10 cardiac myxomas were examined by immunohistochemical analysis for the presence of tryptase-positive mast cells. Statistical analysis of our data demonstrated that angiogenesis and the development of pseudovascular structures were correlated with the number of tryptase-positive mast cells. Therefore, we hypothesize that cardiac myxoma cells are endothelial precursors which are able to generate mature vascular structures. Further morphological and immunophenotypic analyses of tumoral cells may corroborate such a hypothesis.
\end{abstract}

\section{Introduction}

Primary cardiac tumors are rare, with an autopsy incidence ranging from 0.001 to $0.03 \%$ (1). Cardiac myxoma is the most common primary cardiac tumor worldwide, and myxomas may be sporadic or part of genetic conditions, such as Carney complex or lentigines, atrial myxoma and blue nevi syndrome $(2,3)$.

Microscopically, myxomas exhibit a myxoid stroma with plump spindle or stellate cells. Such elements have endothelial characteristics and may be organized into pseudovascular

Correspondence to: Professor Giuseppe Donato, Department of Pathology, School of Medicine, University Magna Graecia, Policlinico Universitario Mater Domini, 115 Via T. Campanella, Catanzaro I-88100, Italy

E-mail: gdonato@unicz.it

Key words: cardiac myxoma, mast cells, tryptase, angiogenesis structures. In certain cases, a variably abundant vascular component may also be present (4).

An increase in the number of mast cells in tumors and a correlation between angiogenesis, mast cell number and growth of the neoplasm has previously been reported (5-7).

Currently, no available studies have demonstrated that the pathological characteristics of cardiac myxomas, such as cell differentiation and vascularization, are correlated with the angiogenic factors of mast cells. In the present study, via immunohistochemical analysis, the role of mast cell tryptases in cardiac myxomas was investigated using a series of 10 cardiac myxomas (8). Furthermore, the possible association between the tumorigenesis of myxomas and current theories regarding endocardial development were investigated.

\section{Materials and methods}

Materials. Archival formalin-fixed and paraffin-embedded tissues were used to study sporadic left atrial myxomas and were collected from 10 consecutive patients (four male and six female patients; mean age, $56 \pm 4.7$ years) who had undergone surgery at the Department of Cardiac Surgery, School of Medicine, University Magna Graecia (Catanzaro, Italy). The study was approved by the ethics committee of the University Magna Graecia (Catanzaro, Italy). Serial deparaffinated sections ( $4 \mu \mathrm{m}$-thick) were used for the staining procedures, including hematoxylin and eosin, Alcian Blue $(\mathrm{pH} 2.5$; Bio-Optica Milano SpA, Milano, Italy) and immunohistochemistry. All the procedures were performed at room temperature. Patients provided written informed consent.

Immunohistochemistry. Mast cells in all cases were then immunohistochemically stained for mouse monoclonal anti-human tryptase (clone 10D11, 1:150 dilution; Leica, Mannheim, Germany), mouse monoclonal anti-human cluster of differentiation (CD)31 (clone JC70A, 1:40 dilution; Dako, Carpinteria, CA, USA), mouse monoclonal anti-human CD34 (clone QBEnd10, 1:250 dilution; Dako) and rabbit polyclonal anti-human CD117 (1:100 dilution; Dako) with an automated immunostainer (Bond ${ }^{\mathrm{TM}}$ Max; Leica Biosystems, Melbourne, Australia) (9).

Blood vessel density was assessed by light microscopy according to the method of Weidner et al (10) and a 
Table I. Morphological patterns and immunohistochemical analysis of myxomas.

\begin{tabular}{rccc}
\hline Case & Morphological patterns & $\begin{array}{c}\text { No. of tryptase-/ } \\
\text { CD117-positive cells }\end{array}$ & $\begin{array}{c}\text { Blood vessel } \\
\text { density score }\end{array}$ \\
\hline 1 & APS, H & $18.4 / 23.0$ & 4 \\
2 & APS, H & $12.6 / 14.5$ & 4 \\
3 & APS & $15.4 / 17.4$ & 4 \\
4 & APS & $7.6 / 11.4$ & 3 \\
5 & SPS & $6.2 / 6.6$ & 2 \\
6 & SPS & $6.0 / 7.4$ & 2 \\
7 & SPS & $8.2 / 10.4$ & 3 \\
8 & SPS & $8.8 / 12.4$ & 1 \\
10 & SPS & $5.4 / 7.0$ & 1 \\
\hline
\end{tabular}

APS, abundant pseudovascular structures; H, hemorrhagic; SPS, scanty pseudovascular structures; CD117, cluster of differentiation 117; ${ }^{a}$ Average calculated from five consecutive tissue slices of each case.

score graded on a scale of one to four was assigned: $1,1-5$ microvessels observed; 2, 6-10 microvessels observed; 3 , 11-15 microvessels observed; 4, 16-20 microvessels observed.

Evaluation of positive cells. The number of mast cells that were tryptase-positive (Fig. 1A) and CD117-positive cells (Fig. 1B) was evaluated according to the method of Benitez-Bribiesca et al (7).

Statistical analysis. Statistical analysis was performed in order to calculate the correlation coefficient using least square regression analysis between the blood vessel density score and the number of tryptase-positive mast cells, as well as the associated P-value.

Histopathological characteristics, such as the presence of pseudovascular structures, abundant ( $\geq 10$ pseudovascular channels in five high power fields; magnification, x400) or scanty $(<10$ pseudovascular channels in five high power fields; magnification, $\mathrm{x} 400$, and the presence or absence of hemorrhages were recorded. Pseudovascular structures were recognized as the lumen lacked red blood cells and was lined by larger, often multinucleated, cells.

Student's t-test was used to compare the number of tryptase-positive mast cells in the two groups of tumors with abundant or scanty pseudovascular structures. In addition, the correlation between the tumor size and the number of tryptase-positive cells was examined by a correlation index. $\mathrm{P}<0.05$ was considered to indicate a statistically significant difference. Analyses were performed using the online 'Statistics to Use' software (http://www.physics. csbsju.edu/stats/).

\section{Results}

Main findings. The immunohistochemical findings and tumor size are summarized in Tables I and II, respectively. Statistical analysis demonstrated a positive correlation between angiogenesis and the number of tryptase-positive mast cells $(r=0.797$; $\mathrm{P}=0.006)$.
Table II. Tumor size $(\mathrm{cm})$.

\begin{tabular}{rl}
\hline Case & Size \\
\hline 1 & 5.8 \\
2 & 3.7 \\
3 & 3.8 \\
4 & 4.9 \\
5 & 3.8 \\
6 & 1.7 \\
7 & 2.3 \\
8 & 2.6 \\
9 & 3.4 \\
10 & 3.5 \\
\hline
\end{tabular}

Results of the statistical analysis. The results of Student's $t$-test allowed us to reject the null hypothesis in our series $(\mathrm{P}=0.009)$ concerning the two groups of tumors with abundant and scanty pseudovascular structures. Moreover, the number of CD117-positive cells, attributed only to mast cells, as basophils, endothelial and neoplastic elements are known to be only feebly positive or negatively stained $(11,12)$, were increased in all the cases compared with the number of tryptase-positive elements, suggesting degranulation of mastocytes (Table I). Tumor size was not correlated with the number of tryptase-positive cells $(\mathrm{r}=0.584 ; \mathrm{P}=0.076)$.

Morphological observations. Qualitative analysis of our series suggests that developing pseudovascular structures may be segregated or intermixed with vessels. Notably, such structures clearly originate from these complex architectures (Fig. 1C and D).

Isolated tumor tissues were CD31- and CD34-positive with an irregular staining distribution on the cell membrane; furthermore, tumor tissues exhibiting vascular and pseudovascular structures were always stained positive for CD31 and CD34 (Fig. 2A and D). 


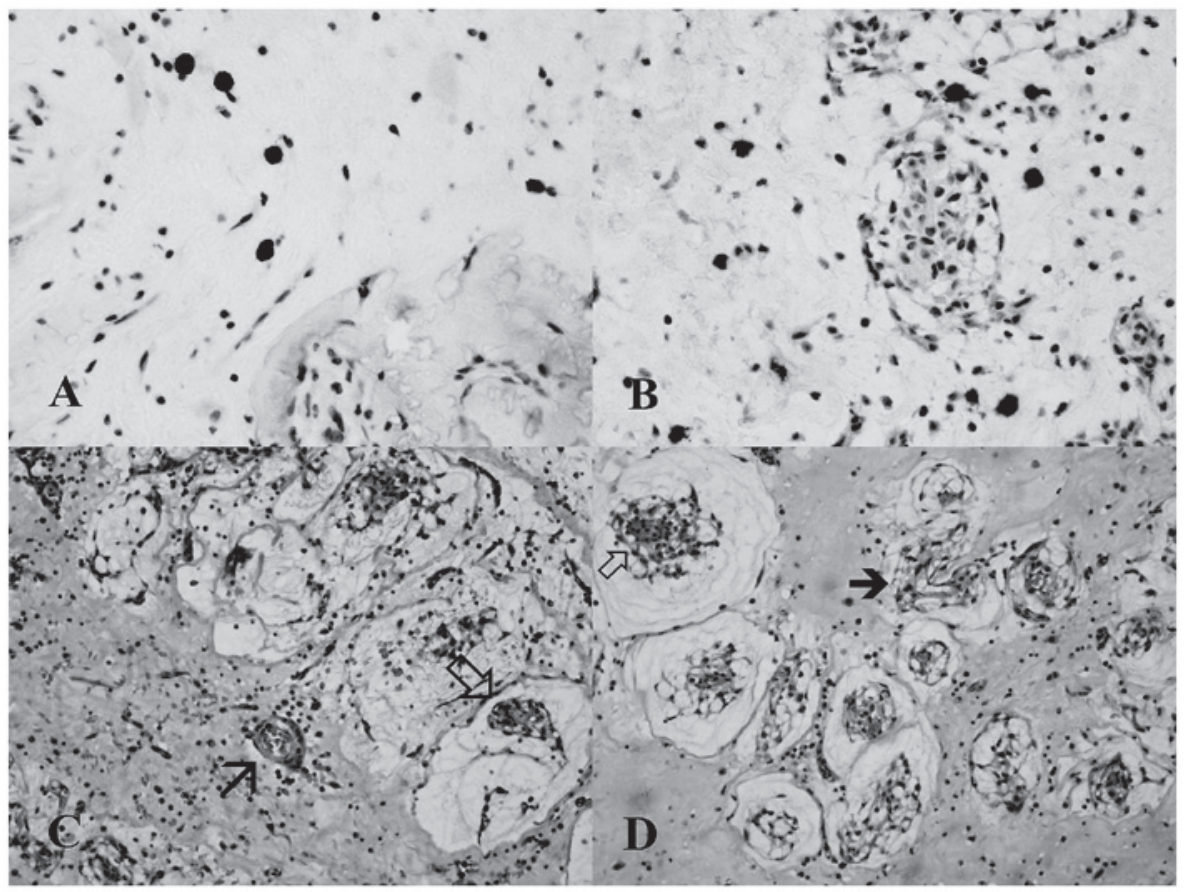

Figure 1. Scattered, dark stained, cellular elements were observed in the immunohistochemical staining of mast cells for (A) tryptase and (B) cluster of differentiation 117. Hematoxylin and eosin staining revealed (C) pseudovascular structures without intermixed vessels (empty arrow) and an isolated vessel-like channel (full arrow), and (D) pseudovascular (full arrow) and vascular structures growing in the same area, and vascular channels developing in the pseudovascular structures (empty arrow). Scale bar, A-D $=100 \mu \mathrm{m}$.

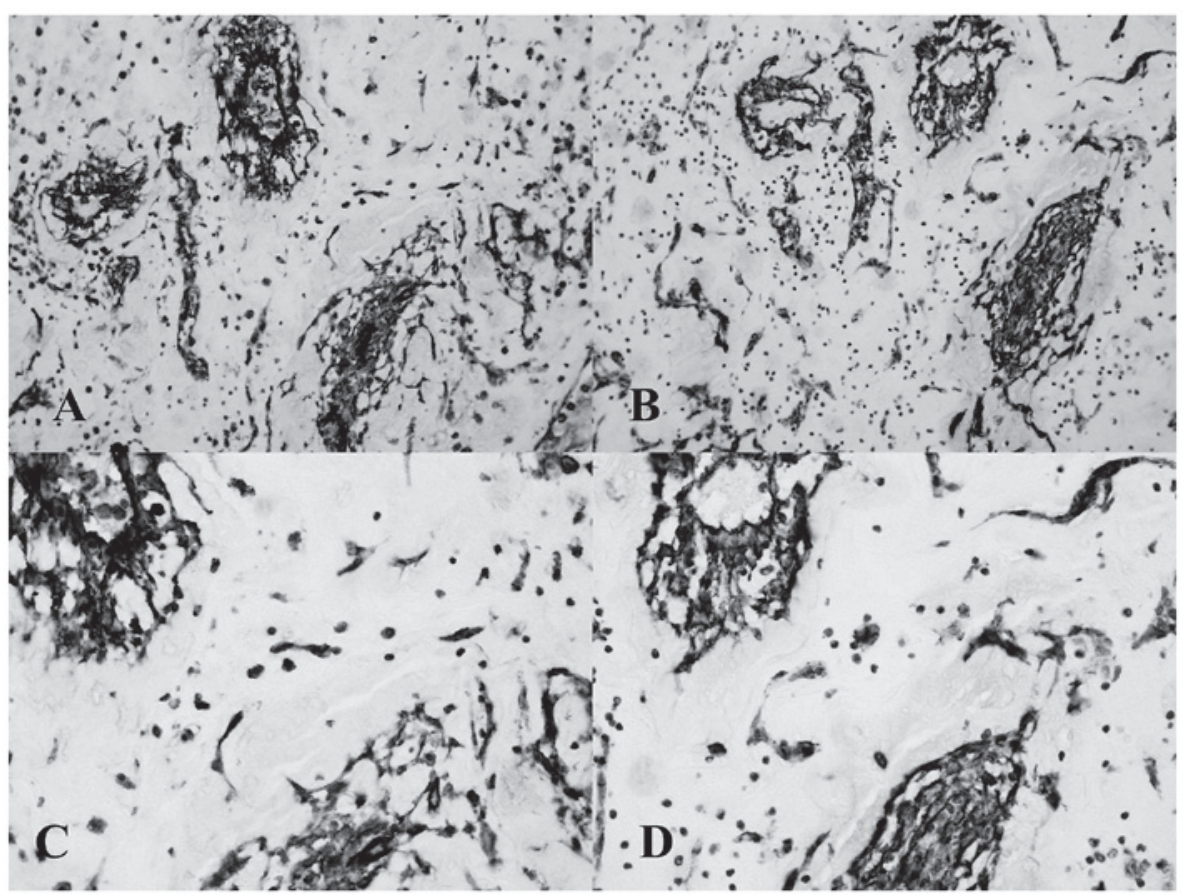

Figure 2. In the same area of a myxoma, pseudovascular structures and scattered tumoral cells stained positive for (A) CD31, (B) CD34 (magnification, x20), (C) CD31 and (D) CD34 (magnification, $\mathrm{x} 40$ ). Scale bars, A and B=100 $\mu \mathrm{m} ; \mathrm{C}$ and $\mathrm{D}=200 \mu \mathrm{m}$. CD, cluster of differentiation.

\section{Discussion}

Cardiac myxoma is a rare neoplasia with an obscure origin; its endothelial characteristics permit us to hypothesize that the factors inducing angiogenesis are also important for the growth and differentiation of this tumor type.
Cardiac tissue typically consists of mast cells in the myocardium and endocardium. Notably, such elements, as well as in cardiac myxomas, are predominantly located in the atrium (13).

Cell receptors and molecules of the extracellular matrix have previously been identified as possible factors of growth and angiogenesis in cardiac myxomas (14). However, previous 
literature has focused on the phenotype of cells, suggesting that cardiac myxoma cells may derive from adult developmental remnants in the presence of myocytic antigens (15). In such a setting, it is important to correlate our data with other available studies. CD117 expression may be considered as a key factor in order to distinguish putative cardiac progenitor cells (negative) from mast cells (positive) in child and adult human hearts (16).

Numerous observations support a model in which the endocardium is a spatially restricted population of the endothelium, arising as a result of de novo vasculogenesis from precursor cells present in the cardiac crescent (17). It is likely that myxoma cells are independent endocardial precursors of endothelial cells expressing CD31 (18).

The pattern of CD34 and CD31 expression and the reciprocal location of vascular and pseudovascular proliferation found in our series, suggests that in cardiac myxomas, endothelial precursors of endocardial type, through an intermediate stage of tumor cells, may also differentiate into vascular endothelia. CD34 is a cell surface glycoprotein expressed on hematopoietic stem and progenitor cells and on the luminal cell membrane of endothelial cells of small blood and lymphatic vessels (19-21). Moreover, a small subset of CD34-positive precursor cells remain present in later passages of primary endothelial cell cultures and also in immortalized endothelial cell lines (22). Such cells have been identified as endothelial elements able to regulate angiogenesis (23). In the present study, the pool of isolated elements of myxomas was CD34-positive. Such elements may be tumoral stem cells with angiogenic properties. Moreover, in our myxoma series, angiogenesis was often intermixed with pseudovascular structures. Thus, the angiogenic factors of mast cells may play a pivotal role in regulating the growth and differentiation of such a primitive endothelial population.

The ambiguous correlation between mast cells and tumors has been previously investigated $(24,25)$ and among the functions of mast cells promoting tumor development, their contribution to neoangiogenesis appears to be highly important. Angiogenesis was measured and microvessels were counted in human endometrial carcinoma (26). The number of microvessels correlated with the number of tryptase-positive cells and these parameters increased with tumor progression. A similar outcome was observed in uterine cervix carcinoma (7), pulmonary adenocarcinoma (27) and gastrointestinal cancers (28). The density of mast cells is also parallel to microvessel density in the progression of gastric carcinoma (29). This correlation was observed for chymaseand tryptase-positive cells.

In conclusion, the present study demonstrated a significant correlation between angiogenesis and the number of mast cells present in cardiac myxomas. As tumors rich in pseudovascular structures contain a significantly higher number of mastocytes, such cellular elements may play a role in the development and differentiation of tumoral cells with an endothelial origin.

Finally, as tryptase is important for tumor progression, the inhibition of this proteinase is a promising technique in patients not surgically treatable. Compounds targeting tryptase, although designed as anti-allergenics, may also exert antitumor effects $(25,30)$.

\section{References}

1. Riberi A, Gariboldi V, Grisoli D, et al: Cardiac tumors. Rev Pneumol Clin 66: 95-103, 2010.

2. Carney JA, Gordon H, Carpenter PC, et al: The complex of myxomas, spotty pigmentation, and endocrine overactivity. Medicine (Baltimore) 64: 270-283, 1985.

3. Rhodes AR, Silverman RA, Harrist TJ, et al: Mucocutaneous lentigines, cardiomucocutaneous myxomas, and multiple blue nevi: the 'LAMB' syndrome. J Am Acad Dermatol 10: 72-82, 1984.

4. Burke AP, Tazeelar H, Gomez-Roman JJ, et al: Benign tumours of pluripotent mesenchyme. In: World Health Organization: Tumours of the Lung, Pleura, Thymus and Heart. Travis WD, Brambilla E, Muller-Hermelink HK and Harris CC (eds). IARC Press, Lyon, pp260-265, 2004.

5. Ribatti D and Crivellato E: The controversial role of mast cells in tumor growth. Int Rev Cell Mol Biol 275: 89-131, 2009.

6. Ribatti D, Crivellato E, Roccaro AM, et al: Mast cell contribution to angiogenesis related to tumour progression. Clin Exp Allergy 34: 1660-1664, 2004.

7. Benitez-Bribiesca L, Wong A, Utrera D, et al: The role of mast cell tryptase in neoangiogenesis of premalignant and malignant lesions of the uterine cervix. J Histochem Cytochem 49: 1061-1062, 2001.

8. McNeil HP, Adachi R and Stevens RL: Mast cell-restricted tryptases: structure and function in inflammation and pathogen defense. J Biol Chem 282: 20785-20789, 2007.

9. Ammendola M, Zuccala V, Patruno R, et al: Tryptase-positive mast cells and angiogenesis in keloids: a new possible post-surgical target for prevention. Updates Surg 65: 53-57, 2013.

10. Weidner N, Semple JP, Welch WR, et al: Tumor angiogenesis and metastasis - correlation in invasive breast carcinoma. N Engl J Med 324: 1-8, 1991.

11. Acebo E, Val-Bernal JF and Gomez-Roman JJ: Thrombomodulin, calretinin and c-kit (CD117) expression in cardiac myxoma. Histol Histopathol 16: 1031-1036, 2001.

12. Arock M, Schneider E, Boissan M, et al: Differentiation of human basophils: an overview of recent advances and pending questions. J Leukoc Biol 71: 557-564, 2002.

13. Sperr WR, Bankl HC, Mundigler G, et al: The human cardiac mast cell: localization, isolation, phenotype, and functional characterization. Blood 84: 3876-3884, 1994.

14. Donato G, Conforti F, Zuccala V, et al: Expression of tenascin-c and CD44 receptors in cardiac myxomas. Cardiovasc Pathol 18: 173-177, 2009.

15. Orlandi A, Ciucci A, Ferlosio A, et al: Cardiac myxoma cells exhibit embryonic endocardial stem cell features. J Pathol 209: 231-239, 2006.

16. Zhou Y, Pan P, Yao L, et al: CD117-positive cells of the heart: progenitor cells or mast cells? J Histochem Cytochem 58: 309-316, 2010.

17. Harris IS and Black BL: Development of the endocardium. Pediatr Cardiol 31: 391-399, 2010.

18. Milgrom-Hoffman M, Harrelson Z, Ferrara N, et al: The heart endocardium is derived from vascular endothelial progenitors. Development 138: 4777-4787, 2011.

19. Andrews RG, Singer JW and Bernstein ID: Monoclonal antibody $12-8$ recognizes a $115-\mathrm{kd}$ molecule present on both unipotent and multipotent hematopoietic colony-forming cells and their precursors. Blood 67: 842-845, 1986.

20. Krause DS, Fackler MJ, Civin CI, et al: CD34: structure, biology, and clinical utility. Blood 87: 1-13, 1996.

21. Nielsen JS and McNagny KM: CD34 is a key regulator of hematopoietic stem cell trafficking to bone marrow and mast cell progenitor trafficking in the periphery. Microcirculation 16: 487-496, 2009

22. van Beijnum JR, van der Linden E and Griffioen AW: Angiogenic profiling and comparison of immortalized endothelial cells for functional genomics. Exp Cell Res 314: 264-272, 2008.

23. Siemerink MJ, Klaassen I, Vogels IM, et al: CD34 marks angiogenic tip cells in human vascular endothelial cell cultures. Angiogenesis 15: 151-163, 2012.

24. Theoharides TC and Conti P: Mast cells: the Jekyll and Hyde of tumor growth. Trends Immunol 25: 235-241, 2004.

25. Dyduch G, Kaczmarczyk K and Okon K: Mast cells and cancer: enemies or allies? Pol J Pathol 63: 1-7, 2012. 
26. Ribatti D, Finato N, Crivellato E, et al: Neovascularization and mast cells with tryptase activity increase simultaneously with pathologic progression in human endometrial cancer. Am J Obstet Gynecol 193: 1961-1965, 2005.

27. Takanami I, Takeuchi $\mathrm{K}$ and Naruke M: Mast cell density is associated with angiogenesis and poor prognosis in pulmonary adenocarcinoma. Cancer 88: 2686-2692, 2000.
28. Ammendola M, Sacco R, Donato G, et al: Mast cell positivity to tryptase correlates with metastatic lymph nodes in gastrointestinal cancer patients treated surgically. Oncology 85: 111-116, 2013.

29. Ribatti D, Guidolin D, Marzullo A, et al: Mast cells and angiogenesis in gastric carcinoma. Int J Exp Pathol 91: 350-356, 2010.

30. Groot Kormelink T, Abudukelimu A and Redegeld FA: Mast cells as target in cancer therapy. Curr Pharm Des 5: 1868-1878, 2009. 